\title{
Hypopharyngeal Cancer pTO TNM Finding v6 and v7
}

National Cancer Institute

\section{Source}

National Cancer Institute. Hypopharyngeal Cancer pTo TNM Finding v6 and v7. NCI

Thesaurus. Code C64447.

Hypopharyngeal cancer with no evidence of a primary tumor. (from AJCC 6th and 7th Eds.) 